\title{
Health-related quality of life in children with sickle cell disease: a concept analysis
}

\author{
Yusra Al Nasiria* and Adhra Al Mawalib
}

\author{
aman College of Health Sciences, Nursing Program, Ministry of Health, Muscat, Oman. \\ ${ }^{b}$ Center of Studies \& Research, Ministry of Health, Muscat, Oman. \\ *Correspondence to Dr. Yusra Al Nasiri (email: yusra444@hotmail.com). \\ (Submitted: 05 November 2018 - Revised version received: 22 November 2018 - Accepted: 06 December 2018 - Published online: 26 February 2019)
}

\begin{abstract}
Objective The purpose of this concept analysis is to examine the health-related quality of life in children with sickle cell disease.
Methods Meleis's concept analysis methodology was followed for analyzing health related quality of life concept. This includes defining the concept, clarifying ambiguities, describing the critical attributes, identifying the observable and measurable empirical referent, delineating the antecedents, the consequences, and modeling to illustrate the concept in its entirety. Articles focusing on quality of life, health-related quality of life (HRQOL) in children with sickle cell disease (SCD) were examined.

Results The concept appears well developed and the internal characteristic of HRQOL is delineated. To ensure that its characteristics maintained contextual relevance, a concept called 'fine tune' should be done. Since HRQOL concept is a multidimensional concept, a factor analysis test may be needed to explore the dimensionality and the structure of its meaning. Also, internal consistency reliability needs to be done to assess the items independence of one another.

Conclusion Successful patient outcomes is an important goal for nursing and it is critical to health care decision making for practical, ethical, and financial. The analysis of HRQOL concept provided more clarity to the concept definition and also to the underlying outcome measures. Naming the variables of the concepts clearly facilitates comparing and contrasting the healthcare interventions on various patients' outcomes. In addition, by examining the concept in children with SCD, pediatric nurses become more cognizant of the concept's meaning that would easily facilitate the understanding of the children's and their parents' perception of HRQOL.

Keywords concept analysis, health related quality of life, sickle cell disease
\end{abstract}

\section{Introduction}

Sickle cell disease (SCD) is a chronic, inherited hematological disorder that is associated with life-threatening complications that affect all major systems (Stuart and Nagel, 2004). Frequent painful crises, infections, acute chest syndrome, priapism, splenic sequestrations stroke, and organ failure are the most common complications affecting children with SCD. ${ }^{1,2}$

Sickle cell disease has many complications that impact all aspects of children's life, which include the physical, psychological, social, and mental. Determining health-related quality of life (HRQOL) provides an understanding of SCD burden on those children. ${ }^{3,4}$ It helps providing information to families, and health care providers regarding the impact of the disease on children with SCD. Measuring HRQOL is considered as an important indicator to evaluate health care interventions and treatments. ${ }^{4}$ This in turn, will provide opportunities to identify patients' responses to treatment, and tailor appropriate therapies based on the patients' perspective of their HRQOL. ${ }^{5}$ In clinical practice, HRQOL information can be useful in identifying and prioritizing health problems for individual SCD cases as well as facilitates identifying any hidden or unexpected health problems. Thus, it aids to decision-making, and in monitoring the health status of the patients. ${ }^{4}$ It was also found that, measuring HRQOL has shown to improve communication between patients and providers as well as create a patient-centered environment. In addition, HRQOL is considered as an important predictor for morbidity and mortality outcomes. ${ }^{1}$ Therefore, understanding HRQOL concept and clarifying its theoretical and practical aspects is very important for nursing practice. Concept analysis method will help clarifying the concept and define its meaning that could be clearly understood by pediatric nurses when dealing with children having SCD. Also, analyzing HRQOL concept would lead to the development of disease specific measurement tools for the concept to be utilized specifically for children with SCD.

The concept "QOL" is a commonly used concept across different disciplines. Initially, QOL was applied in sociology but later it was applied to other disciplines. Although QOL is used in everyday language, it is viewed as a multifaceted concept. ${ }^{6}$ QOL and HRQOL have been used inter-changeably and remain vague and unclear concepts. The concept HRQOL referred and used widely in healthcare literature. It is considered as a fundamental concept in health care because one of the nursing goals is to enhance the health outcomes and strive to provide quality of care for the patients. Therefore, focusing on QOL and the issues that might affect it can lead to improve nursing care through recognizing the effect of the diseases, evaluating treatments, and facilitating resource decision. ${ }^{7}$ Although HRQOL concept is frequently used, it has still remained unclear and not well defined and often confused with QOL concept. Concept analysis is considered as a means to clarify vague and overused concept and also to distinguish the concept from other similar concepts. Therefore, the purpose of this analysis is to clarify the meaning of HRQOL through reviewing the literature. The concept analysis in this paper will be guided by the guidelines presented in Meleis model for the concept analysis. ${ }^{8}$ Meleis model has been used widely in nursing and found to be clear and easy to follow. First, a literature was reviewed to examine the uses, define the concept, clarify ambiguities and describe the critical attributes of the concept. Second, the observable and measurable 
empirical referent of the concept was identified. Third, the concept was differentiated from other concepts. Then, the antecedents and the consequences that may result from HRQOL was delineated. At last, modeling was used to illustrate the concept in its entirety. ${ }^{27,28}$

\section{Search Strategy}

Different databases were searched which include PubMed, CINHAL, PsychInfo, Google Scholar, and ERIC using the key term "HRQOL" and "SCD". There were many articles found on HRQOL; therefore, the search was limited to include articles published between 2000 and 2017. Only research articles were included in this review. Studies done on children with SCD were included. The studies that did not give a clear definition of the concept were excluded. Also, one article was chosen from the articles written by the same author. A total of 16 articles were included in this review.

\section{Use of the Concept (HRQOL)}

Health-related quality of life emerged as an important and distinct perspective after the appraisal of QOL concept. Therefore, HRQOL concept was narrowed as a measurable concept because it was found that, most of the outcomes of QOL have no corresponding interventions. ${ }^{6}$ Therefore, QOL was given a new label as HRQOL to facilitate the concept measurement. Based on the reviewed literature, the concept tends to be widely used in the healthcare setting; more specifically for patients with chronic illness.

\section{Definition of the Concept}

In the dictionary, life has been defined as "capacity for growth, existence, and functional activity", quality is referred as "the standard of something when compared with other things like it"? The term quality can have both positive or negative features but mostly it is viewed as something superior. World Health Organization defined QOL as "Individuals" perceptions of their position in life in the context of the culture and value systems in which they live and in relation to their goals, expectations, standards, and concerns". According to Centers for Disease Control and Prevention (CDC), QOL is a broad, multidimensional concept that includes subjective evaluations of the positive and the negative aspects of life. ${ }^{10}$ On the other hand, HRQOL-based (CDC) refers to the individual health' perception of the physical, mental functional status, social, and socioeconomic status. In the reviewed literature, HRQOL is being defined as a multidimensional concept which encompasses domains related to physical, emotional, social, and cognitive functioning. ${ }^{1,3,11-17}$

Some literature specified that, HRQOL goes beyond the direct measures of health, their life expectancy, and the causes of death. ${ }^{2,5}$ It focuses on health impact on the QOL.

\section{Characteristics of HRQOL}

Exploring the literature revealed that the concept of HRQOL was viewed HRQOL in patients with SCD as a multidimensional concept and identified the aspects of it that includes physical, cognitive, social, and emotional.,3,11-13,15-19 Most of the literature cited the subjective nature of HRQOL as the core attribute for this concept and is viewed as the subjective evaluation of the individuals for their health and lives as well as the subjective perception of personal thoughts, feelings, and the meaning of one's life. ${ }^{2,3,11-13,15-19}$ In addition, HRQOL concept is viewed as the well-being of the individual. Satisfaction in life is also seen to be associated with HRQOL..$^{2,3,5,17,20-22}$ The last important characteristic for HRQOL concept is that it is a dynamic concept, it is changing and depends on the context in which it is measured.

\section{Dimensions of the HRQOL (Critical Attributes)}

The critical attributes are the recurrent characteristics of the concept. ${ }^{8}$ The critical attributes of HRQOL are as follows:

\section{Multidimensional}

This includes the physical, psychological, social functioning. Some researchers included the cognitive functioning or the mental capacity to evaluate ones' health or life. ${ }^{5,12-15,17,19,22}$ The physical functioning domain includes the effect of the disease on the physical aspect of health such as walking, running, lifting heaving items, doing exercises, feeling pain, and energy status. The emotional functioning domain includes the effect of the disease on the children's emotions and feelings such as fear, sadness, worry, angry, and sleep disturbance. The social domain includes the individual's interaction and also the relationship with families, peers, and others. The cognitive domain includes the children's memory, attention, and ability to keep up with the school requirement and attendance.

\section{Subjective Nature}

All of the literature indicated that HRQOL is a subjective evaluation and assessment of one's QOL..$^{1-4,11-13,15-19,23}$ It depends on the person's perception, satisfaction, and well-being. As in chronic illness like SCD, pain is subjective and can be best determined by the children and their parents.

\section{Contextual}

Health-related quality of life is a dynamic concept, and it varies based on the context in which it is measured and varies according to the changes in the circumstances. It depends on the situation and the time.

\section{Intangible}

Health-related quality of life is all about personal perception of well-being, satisfaction, and the perception of the effect of the illness on aspects of QOL.

\section{Health-related}

This concept is viewed as related to health and it is an important goal of nursing toward patients with chronic illness. ${ }^{2-4,6,8,15-18}$

\section{Empirical Referents}

Empirical referents are the categories in the phenomena; which demonstrate the existence of the concept and that it is really present. For HRQOL, the empirical referents are the measures of the attributes. It is the statement of the patients; for example, statement about their satisfaction or dissatisfaction. The measurement is dependent on the researchers' conceptualization of HRQOL and also how it is operationalized. 
Therefore, the way it is defined determines what will be included in the assessment measurement. Generally, HRQOL measurement it is a subjective assessment of the individual's well-being and also about one's perception to what degree be able to perform different facets of life. The measurements include the perception of the physical functioning and to which extent one is able to perform activities and if the roles in daily activities are impeded; so the QOL is influenced by the individual's physical status or condition. The second measurement for HRQOL is assessing to which extent the emotional status of the individuals limits the daily functioning and the ability to perform their roles. For the social functioning, the social activities, the interactions, and relationship with each other are assessed. At last, the individual's perception of general health is measured. There are many instruments developed to measure HRQOL, which may reflect the ambiguity of the concept. Some instruments are so generic that is suitable for all population. Others are specific tools, either diseasespecific or specific to certain population such as children or elderly, it is important to identify the rationale behind the choice of the tool. . $^{2-11-13,15-19,24}$

\section{Differentiating HRQOL Concept from other Concepts}

The concept HRQOL is often confused with other concepts such as the general status of health, functional ability, utility, mood, and symptoms. Health is being defined by WHO as "a state of physical, mental, social well-being but not merely the absence of the diseases". However, there is a recent conceptualization of health that makes it so definite as a state that including both the wellness and illness. Functional ability is also confused with QOL. It is considered as a health-related variable and was defined as the ability of the individuals to meet their basic needs, fulfill their roles, and maintain their well-being. ${ }^{7}$ A distinguish was made between the functional capacity and functional performance to make the concept more one's perception of abnormal physical, emotional, and cognitive status. HRQOL is often negatively correlated with the physiological abnormality which is an objective measure. Mood is the affective domain of the individual which includes happiness, sadness, depression, and anxiety. Utility is a concept that is not often used in the health care, but it is applied to health care decision-making to measure the preference for health status. The decision of the individual is thought to be based on the anticipated satisfaction of the individual or QOL. QOL is a multidimensional concept that includes physical, psychological, social, and cognitive domains of health, general well-being, satisfaction, and role functioning. ${ }^{2,3,13,15,17-19,22}$ However, the term QOL found to be a very broad concept, and the confusion occurred when many outcomes of this concept were broad and had no corresponding interventions. Therefore, when confusion occurred and the same variables are measured every time by the researchers (functional performance, symptoms, physiological dysfunction), the new concept "health-related quality of life" or "HRQOL" has emerged later in the literature. In response to the confusion of the measurement related to QOL outcome, a new concept was developed and narrowed to the QOL that is related to health status and health care to link some parts of life that is influenced by health. A new label was given which is "HRQOL" that mainly focuses on the physical, psychosocial, and cognitive health dimensions. ${ }^{25}$

\section{Delineating Antecedents of HRQOL Concept}

The contextual condition under which HRQOL is perceived and is expected to occur is "life". The concept "QOL" is always present, but it can occur only when life begins. Since this concept is multidimensional and it is value-based and subjective in nature, then the ability to evaluate one's self and make a decision in regards to life or may be treatments can be considered another antecedent for the concept HRQOL. Therefore, the ability of the individual to perform the cognitive evaluation of self or and to be conscious about his status is important antecedent; for example, sometimes the adolescents with chronic illness may make a decision regarding their treatments without the willingness of their parents to find a way to cope with their illness. Also, they find their own ways of coping to go on with living.

\section{Delineating Consequences of HRQOL Concept}

Consequences are the conditions that preceded by the evaluation of HRQOL concept. The consequence of HRQOL concept can be related to the consequences that occur after individual's evaluation or individual perception of HRQOL (such as satisfaction) and the decision that might result in making a change in the individual's circumstances; for example, when the individual evaluates HRQOL as high, it means he is satisfied and happy in life. It may also mean that he is empowered because he has high self-esteem about his life his physical and psychosocial health is good. However, the negative consequence of individual's perception or evaluation of HRQOL as poor is that, it might result in, dissatisfaction, low self-esteem, low coping abilities, changes in self-concept, depressed, isolated and it may even have extended to risk-taking as in adolescents with chronic illness.

\section{Modeling HRQOL Concept}

The author illustrates two exemplars for HRQOL using a model case and a contrary case.

\section{A model case}

Maya is a 12-year-old child diagnosed with SCD. Maya seldom gets pain and looks physically healthy. She has many friends and looks satisfied with life.

\section{A contrary case}

Dana is a 12-year-old child diagnosed with SCD. Dana gets frequent pain crisis and required frequent admissions, she is isolated and does not have friends. She wrote a storybook recently and won, but she did not want the gift and planned not to go and get the gift. She is dissatisfied with her life.

\section{Analogizing}

Health-related quality of life can be described as the "perception of well-being or ill-being". So, when the individual perceive himself as being well it indicates that he remained healthy (physically, mentally, socially and emotionally) and therefore, he is seen to have a good HRQOL and when the person perceives himself being ill, it indicates that he thinks that his health is interrupted either (physically, mentally, socially and emotionally) and, therefore, he can be seen as having poor HRQOL. 


\section{Synthesizing}

Health-related quality of life is a multidimensional concept that describes the physical, emotional, social, and cognitive health functions of the patients with chronic illness.

\section{Assumptions}

In the analysis of this paper, two assumptions have been made. The first assumption is that the conceptual clarity is essential to guide high-quality research and for patient care. Lack of conceptual clarity may lead to chaotic studies on patient care outcomes. ${ }^{26}$ Therefore, if HRQOL demonstrates to be a clear concept then the patient outcomes that the author's research will focus on in the future will be accurately identified and, therefore, appropriate interventions can be designed responding to those outcomes. The second assumption is that in the measurement tool, the operationalization of the concept must very closely represent the conceptual definitions. It is essential that the instrument items must reflect the whole entirety of the concept emotional. ${ }^{26}$ In the literature, there are different instruments developed to measure HRQOL; therefore, this may affect the coherence of the concept's meaning if all these instruments, in fact, measure HRQOL. Failure to define HRQOL concept may lead to chaos in the health care literature and may result in the development of different tools. Considering these two assumptions, this paper analysis attempted to capture the richness of HRQOL concept as it is defined and distinguish HRQOL concept from other common variables that are measured under the rubric of HRQOL.

\section{Conclusion}

Conducting a concept analysis enhanced the understanding of HRQOL concept. The examination of its usage, critical attributes, antecedents, consequences and cases illustration provided insight into the essence of HRQOL concept. The concept HRQOL is considered as a very important phenomena in nursing practice. It is significant for nurses working in pediatric settings. By examining the concept in children with SCD, pediatric nurses become more cognizant of the concept's meaning that would easily facilitate the understanding of the children's and their parents' perception of HRQOL. Successful patient outcomes is an important goal for nursing and it is critical to health care decision making for practical, ethical, and financial. The analysis of HRQOL concept provided more clarity to the concept definition and also to the underlying outcome measures. Naming the variables of the concepts clearly facilitates comparing and contrasting the healthcare interventions on various patients' outcomes. In addition, identifying the variables of HRQOL and understanding the relationship between them provides clarity about the effect of the intervention on the outcomes. HRQOL is an important concept in nursing because patients' QOL always matters; so being responsive and sensitive to patients' perception of their QOL helps to intervene to obtain a positive impact.

Health-related quality of life concept is helpful for generating nursing theory because by understanding the nature of the phenomena and anticipating its occurrence, identifying the concept antecedents, consequences, variables or attributes and understanding the relationship between them, this lead to link the concepts of the phenomena together and serve as a building blocks to generate a theory. There are many attributes identified from the concept HRQOL and the relationship between them can be easily described and explained. Therefore, linking the variables of HRQOL, the antecedents, and the consequences and identifying the relationship among them can set a building blocks for a model or a theory that can serve as a guideline that influences nursing care.

Health-related quality of life unlike the QOL concept, HRQOL can be considered matured and a well-developed concept because there is a consistency present across the health care literature about its conceptualization of definition. Also, the conceptual characteristics and attributes of HRQOL are present and agreed upon. In addition, HRQOL dimensions, boundaries as well as the potential indicators are identified. However, there are many instruments developed to measure HRQOL and this in fact suggests that a refinement of the conceptualization is needed to be done as the validity of the conceptualization across the population has not been established yet. Although the concept appears well developed, the internal characteristics of HRQOL was not clearly delineated. Therefore, to ensure that its characteristics maintained contextual relevance, a concept called "fine tune" should be done. Therefore, a further study on this concept would be refining the HRQOL instrument and test its psychometric properties using a quantitative approach. Since HRQOL concept is a mutli-dimensional concept, a factor analysis test may be needed to explore the dimensionality and the structure of its meaning. Also, internal consistency reliability needs to be done to assess the items independence of one another.

\section{Acknowledgment}

I would like to thank Professor Betty Chang, UCLA, for the valuable input provided in this paper.

\section{Conflicts of Interest Disclosure}

None.

\section{References}

1. Brousscau DC, Panepinto J, Nimmer M, Hoffmann RG. The number of people with Sickle cell disease in the United States: National and State estimates. Am J Hematol. 2010;85:77-78.

2. Sawyer MG, Reynolds KE, Couper J, French D, Kennedy D, Martin J, et al. A two-year prospective study of the health-related quality of life of children with chronic illness--the parents' perspective. Qual Life Res. 2005:14:395-405.

3. Strine TW, Chapman DP, Balluz LS, Moriarty DG, Mokdad AH. The associations between life satisfaction and health-related quality of life, chronic illness, and health behaviors among U.S. community-dwelling adults. J Community Health. 2008:33:40-50.
4. Taylor RM, Gibson F, Franck LS. A concept analysis of health-related quality of life in young people with chronic illness. J Clin Nurs. 2008;17:1823-1833.

5. Palermo TM, Schwartz L, Drotar D, McGowan K. Parental report of health-related quality of life in children with sickle cell disease. J Behav Med. 2002;25:269-283.

6. Hijmans CT, Fijnvandraat K, Oosterlaan J. Double disadvantage: a casecontrol study on health-related quality of life in children with sickle cell disease. Health Qual Life Outcomes. 2010;8:121. doi:10.1186/1477-7525-8121. PubMed PMID: 20977722. PubMed Central PMCID: PMC2988059.

7. Wrotniak BH, Schall J, Brault M, Balmer D, Stallings V. Health-related quality of life in children with sickle cell disease using the child health questionnaire. J Pediatr Health Care. 2014;28:14-22. 
8. Morse JM, Mitcham C, Hupcey JE, Tason M C. Criteria for concept evaluation. J Adv Nurs. 1996;24:385-390.

9. World Health Organization. 2010. Available from: http://www.who.int/ about/definition/en/print.html (accessed February 2015).

10. Centre for Disease and Control Prevention (CDC). Available from: http:// www.cdc.gov/hrqol/ (accessed February 2015).

11. Ameringer S, Elswick RK, Smith W. Fatigue in adolescents and young adults with sickle cell disease: biological and behavioral correlates and healthrelated quality of life. J Pediatr Oncol Nurs. 2014;31:6-17. Available from: https://www.ncbi.nlm.nih.gov/pmc/articles/PMC3982311/.

12. Beverung $L M$, Varni JW, Panepinto JA. Clinically meaningful interpretation of pediatric health-related quality of life in sickle cell disease. J Pediatr Hematol Oncol. 2015:37:128-133. doi:10.1097/MPH.0000000000000177

13. Fisak B, Belkin MH, Lehe AC, Bansal MM. The relationship between healthrelated quality of life, treatment adherence and disease severity in pediatric sickle cell disease sample. Child Care Health Dev. 2010;38:204-210. doi:10.1111/j.1365-2214.2011.01223.x. PubMed PMID: 21434965

14. Garratt A, Schmidt L, Mackintosh A, Fitzpatrick R. Quality of life measurement: bibliographic study of patient assessed health outcome measures. BMJ. 2002;324:1417.

15. Jackson JL, Lemanek KL, Clough-Paabo E, Rhodes M. Predictors of health-related quality of life over time among adolescents and young adults with sickle cell disease. J Clin Psychol Med Settings. 2014;21: 313-319.

16. Limbers CA, Skipper S. Health-related quality of life measurement in siblings of children with physical chronic illness: a systematic review. Fam Syst Health. 2014;32:408-415.

17. Schlenz AM, Schatz J, McClellan CB, Roberts CW. Responsiveness of the PedsQL to pain-related changes in health-related quality of life in pediatric sickle cell disease. J Pediatr Psychol. 2012;37:798-807.
18. Dampier C, LeBeau P, Rhee S, LieffS, Kesler K, Ballas S. Health related quality of life in adults with sickle cell disease (SCD): a report from the comprehensive sickle cell centers clinical trial consortium. Am J Hematol. 2011:86:203-205. doi:10.1002/ajh.21905. PubMed PMID: 21264908. PubMed Central PMCID: PMC355439.

19. Lowry TJ, Pakenham KI. Health-related quality of life in chronic fatigue syndrome: predictors of physical functioning and psychological distress. Psychol Health Med. 2008;13:222-238.

20. The Oxford English Dictionary. Clarendon Press, UK, London, 1989.

21. Wilson IB, Cleary PD. Linking clinical variables with health-related quality of life: a conceptual model of patient outcomes. JAMA. 1995;273:59-65.

22. Ziadni M, Patterson C, Pulgaron E, Robinson M, Barakat L. Health-related quality of life and adaptive behaviors of adolescents with sickle cell disease: stress processing moderators. J Clin Psychol Med Settings. 2011;18:335-344. doi:10.1007/s10880-011-9254-3. PubMed PMID: 21681659.

23. Dale JC, Cochran CJ, Lmswap EJ, Buchanan GR. Health-related quality of life in children with sickle cell disease. J Ped Health Care. 2011;25:208-210.

24. Gill TM, Feinstein AR. A critical appraisal of the quality of quality-of-life measurements. JAMA. 1994;272:619-626.

25. Haas BK. A multidisciplinary concept analysis of quality of life. West J Nurs Res. 1999;21:728-742.

26. Meleis A. Theoretical Nursing: Development and Process. $5^{\text {th }}$ Ed.; J. B. Lippincott, Williams \& Wilkins, Philadelphia, 2012.

27. Muszalik M, Kędziora-Kornatowska K, Kornatowski T. Functional assessment and health-related quality of life (HRQOL) of elderly patients on the basis of the functional assessment of chronic illness therapy (FACIT)-F questionnaire. Arch Gerontol Geriatr. 2009:49:404-408.

28. Panipento JA, O'Mahar KM, DeBaun MR, Loberiza FR, Scott JP. Healthrelated quality of life in children with sickle cell disease: child and parents perception. Br J Haematol. 2005;130:437-444. 